This item was submitted to Loughborough's Research Repository by the author.

Items in Figshare are protected by copyright, with all rights reserved, unless otherwise indicated.

\title{
Development of a nanodiamond-based lubricant for a versatile use in the beverage industry conveyor systems
}

PLEASE CITE THE PUBLISHED VERSION

http://dx.doi.org/10.1108/ILT-02-2016-0022

PUBLISHER

(C) Emerald

VERSION

AM (Accepted Manuscript)

\section{PUBLISHER STATEMENT}

This work is made available according to the conditions of the Creative Commons Attribution-NonCommercialNoDerivatives 4.0 International (CC BY-NC-ND 4.0) licence. Full details of this licence are available at: https://creativecommons.org/licenses/by-nc-nd/4.0/

\section{LICENCE}

CC BY-NC-ND 4.0

\section{REPOSITORY RECORD}

Torres, Carmen, and Nikolaos Balodimos. 2019. "Development of a Nanodiamond-based Lubricant for a Versatile Use in the Beverage Industry Conveyor Systems". figshare. https://hdl.handle.net/2134/22367. 

Industrial Lubrication and Tribology

Development of a nanodiamond-based lubricant for a versatile use in the beverage industry conveyor systems

\begin{tabular}{|r|l|}
\hline Journal: & Industrial Lubrication and Tribology \\
\hline Manuscript ID & ilt-02-2016-0022.R1 \\
\hline Manuscript Type: & Original Article \\
\hline Keywords: & $\begin{array}{l}\text { Nanodiamond, poly alpha olefin oil, mineral oil, beverage conveyor system, } \\
\text { Lubrication }\end{array}$ \\
\hline \multicolumn{2}{|c}{} \\
\hline
\end{tabular}


Development of a nanodiamond-based lubricant for a versatile use in the beverage industry conveyor systems

\begin{abstract}
Purpose: This paper proposes the formulation of a nanodiamond particle-loaded food-grade lubricating oil, a nanolubricant, that can be used over a broad range of loads within the factory (low load applications: conveyor systems; and heavy machinery within the factory were high loads are applied)

Design/Methodology: Tribological performance of the nanolubricant at both load levels was studied. A factory-sized conveyor was employed for the low load range using typical beverage packaging (aluminium cans, glass and PET bottles). Coefficients of friction and wear scars were measured and the lubricating performance quantified. A four-ball tester was used to characterise the performance of the nanolubricant as per ASTM D2783/D4172. A comparison between the nanolubricant and the baseline oils was established.
\end{abstract}

Findings: The results show an overall decrease of the coefficients of friction and wear scars for all packages at low pressures when the nanolubricant is used. It also shows a better friction-reduction performance in the high loads. The results indicate that the nanolubricant is versatile at both ranges of loading.

Practical/Environmental implications: The current protocols for lubrication in the food and drink factories involve the use of water-based detergents for the conveyor lines, and industry-grade oils for the machinery. The use of a single and versatile lubricant for both ranges of application loads may carry a positive impact on the sustainability and environmental performance of the sector.

Originality/value: Beverage processing and packing factories need their mechanised conveyor systems suitably lubricated to avoid excessive friction between the containers and the load bearing surface of the conveyors (e.g. belts or chains). Other areas of the conveying systems, such as motors, gears, rollers and bearings, are also in need of suitable lubrication to prevent failure and lengthen their working life. There is a myriad of lubricants and lubricating solutions for each of these areas independently, but no existing availability of commercial lubricating fluids that could be used on both successfully.

Keywords - Nanodiamond, poly alpha olefin oil, mineral oil, beverage conveyor system, lubrication

Paper type - research paper 


\section{Introduction}

Filling, capping, labelling, sealing, packing and discharge stations on beverage processing lines are areas in the factory where cans, plastic and glass bottles and jars remain stationary while the belts and chains move linearly underneath. Damages (e.g. scaring, scratches, scuffing, peeling off) to the packages result in production loss and waste. Packaged food and drink compete in the very crowded market of fast moving consumer goods, so any defect on the packaging or label is perceived as detrimental to the brand. In order to avoid undesirable flaws caused by the transport in the filling/packaging lines, lubrication solutions are applied. These can consist of solid (e.g. graphite, PTFE and metal dichalcogenides [1] (i.e. $M X_{2}$, where $M$ is, for instance, molybdenum (Mo) or tungsten (W) and $X$ is sulphur (S) or selenium (Se)) particles scattered or sprayed onto the surfaces subject to friction [2]) and liquid lubrication approaches. The most sought after specifications in the liquid lubricating system are (i) good lubricity to reduce coefficient of friction and wear, (ii) low viscosity which allows easy application (via spraying or pumping), and (iii) compatibility between the lubricant and the beverage packaging material to avoid damage or cracking in transit or in storage, or to inhibit solid precipitates when content and lubricant come into contact in the event of spillage.

The application of concentrated liquid lubricants (typically $<50 \%$ of dispersant [3] and called 'dry' lubrication to distinguish from 'wet' lubrication where the dispersant, typically water, is the main component) has become very popular in the recent years in industries that utilise conveyor systems (e.g. assembly, packaging, sorting, warehousing). However, most of the lubricants applied in the 'dry' regime still suffer from being specific to each application. For example, silicone-based [3] and fluorinecontaining lubricants [4] are good performers with PET bottles (i.e. containers made of ethylene terephthalate homopolymers, copolymers and mixtures) but less effective on glass and metal containers, particularly on a metal surface [3]. Silicone with fatty amines are recommended for glass on stainless-steel [5]. Lubricants that contain amines, alcohols, potassium hydroxide, ammonium salts or mixtures are incompatible with PET containers causing them to crack in transit or storage [6-8]. Applied by brushes and nozzles, PTFE adheres very strongly to the chains and this soiling curb the performance profile of the lubricant gradually [9]. In addition, PTFE has also been shown to produce stress-cracking in PET bottles [4].

The lubricants formulated for use in the food industry conveying systems perform well as long as low load conditions exist and are not necessarily specified for harsher environments. The lubricants available for application in high load conditions are typically mineral oils with anti-corrosion, anti-wear, anti-friction additives in different proportions [10]. In the food industry machinery these oils are used as hydraulic, circulating, cable, chain, spindle, gear and compressor oils for equipment in the service industry. In the most recent years the nanoparticle-containing suspensions in oils have surged as the most promising of the lubricants for high pressure mechanical applications, in particular when the boundary lubrication is the dominant 
regime (i.e. the lubricating fluid film thickness is small and asperities from rubbing surfaces come into contact and wear is high). Although the majority of examples are oil-based, there are also examples of water-based lubricants [11]. The nanometre scale of the particles improves solubility into the oils, compared to the micro scales [12] and there is a voluminous body of work published in the areas of metal nanoparticles [12-15], non-metal nanoparticles dispersed in mineral oils [16-19], in polymeric oils [20, 21], in natural oils [22, 23], in paraffin [24, 25], and with extra additives to improve their anti-wear, anti-friction features [26-29]. The lubrication mechanisms promoted by nanoparticles have been described and can be classified into two [30]: (i) Direct effects on lubrication (physical effect): the nanoparticles act as spacers and produce ball [31] and sliding effects [32] via mechanical entrapment of the particles between the rubbing surfaces (e.g. exfoliation and third body transfers [33]). They may also adhere onto the rubbing surfaces creating a protective film preventing them from direct contact, resulting in a decrease in friction and wear [34]; and (ii) Secondary effect on surface enhancement (chemical effect): there may exist tribo-chemical reactions [35] in which the nanoparticles may react with the material(s) they are rubbing against creating new chemical components that promote a mending or polished effect on the surfaces [18, 36, 37].

One of the nanoparticles already reported which shows a promising future as a lubricant component for the food technology use is the nanodiamond. Its carbon chemistry biodegradability, non-toxicity [38], bearing-like shape promoting sliding rolling as lubrication mechanism [39], solubility in both mineral oil and others $([25,40]$ and feasible production into de-agglomerated [41, 42] and stable dispersions [43] (via the detonation method [44-47]) makes it a suitable candidate for formulations designed for the use in the mechanical services in the food factory and for the occasional contact with food materials and containers (namely H1 USDA approved).

In the search of a versatile lubricating fluid which can be used successfully on both ranges (low and high pressure applications) and on typical beverage packaging, a nanodiamond particle-loaded lubricating commercial and food grade oil, a nanolubricant, has been formulated, characterised and tested to show that the dual performance is achievable. Factory conditions were replicated for the low load values so that these results can faithfully characterise the nanolubricant in its most realistic working conditions. This is a novel way of assessing lubrication features that satisfies both industrialists as well as applied research scientists. Traditional tests performed on lubricants, in accordance with International Standards, were also considered in this study and therefore allowed comparison with the work carried out by others in this area. 


\section{Experimental}

\section{Materials}

The nanodiamond particles used in this study were purchased from Adámas Nanotechnologies (USA). The particle population in the slurry was characterized using a Nanosight LM-10 instrument (Malvern Instruments Ltd, UK) and its stability (i.e. zeta-potential and conductivity) measured using a Zetasizer Nano ZS (Malvern, UK). Figure 1 shows the results from this analysis in which the majority of the particles are $<30 \mathrm{~nm}$. The zeta-potential was $-116 \mathrm{mV}$, conductivity $4.12 \mu \mathrm{S} / \mathrm{cm}$ and electrophoretic mobility of $-6.83 e-3 \mu \mathrm{m} . \mathrm{cm} / \mathrm{Vs}$, values that confirmed full stability of the dispersions. Two commercial oils (Kristol M24, a white mineral oil (Petrochem Carless Ltd, United Kingdom) and a polyalphaolefin oil, SpectraSyn ${ }^{\mathrm{TM}} 6$ (ExxonMobil, USA) were used as the base oils without further treatment. The properties of the oils are listed in Table 1. Samples for tribological tests were prepared by dispersing $0.01 \%$ wt ratio of nanodiamonds in the base oil. This concentration was informed by previous studies [48]. As a comparison, the tribological properties of the base oils without carrying the nanodiamonds or additives, in their pure form, were also evaluated. The rheological characteristics of the nanolubricants were measured using a Brookfield Rheometer DV-II+ Pro with a RV-1 spindle at a spindle speed of $60 \mathrm{rpm}$. For the low load 'factory-like' conditions, the friction force was measured by means of the sliding force of the conveyor when the packages were under motionrestricted mode. A digital force gauge (Mecmesin Ltd, UK) collected sliding forces at a $10 \mathrm{~Hz}$ sampling rate as shown in Figure 2. This allowed the calculation of the coefficient of friction (COF) under low load schemes using equation (1), with force $F$ being the load $(\mathrm{N})$ registered by the force gauge, ' $i$ ' the number of packs, $g$ the gravitational constant $\left(\mathrm{m} / \mathrm{s}^{2}\right)$ and mass $\mathrm{m}$ the average value $(\mathrm{kg})$ of the packs used in each run.

$$
C O F=\frac{F}{i \cdot g \cdot m}
$$

The wear scar surfaces were inspected by high resolution scanning (2400dpi) on and EPSON Perfection Scanner 1640SU and the results analysed with ImageJ (W. Rasband, 1997, National Institutes of Health, USA). For the high load schemes, the lubricants load-carry capacity - and more specifically the load wear index (LWI) and the weld load $\left(P_{D}\right)$ - were measured in a four ball tribometer according to ASTM D2783. Measurements of the wear-preventing characteristics of the lubricants were assessed as per ASTM D4172. 
Table 1: Rheological properties of the base oils

\begin{tabular}{|c|c|c|}
\hline & Mineral oil & PAO oil \\
\hline Commercial name & Kristol M24 & SpectraSyn 6 \\
\hline $\begin{array}{l}\text { Kinematic viscosity } \\
\left(\mathrm{mm}^{2} / \mathrm{s}\right) 40^{\circ} \mathrm{C}\end{array}$ & 36.0 & 30.0 \\
\hline Pour point $\left({ }^{\circ} \mathrm{C}\right)$ & -6 & -57 \\
\hline Flash point $\left({ }^{\circ} \mathrm{C}\right)$ & 180 & 249 \\
\hline Specific gravity (at $15^{\circ} \mathrm{C}$ ) & 0.859 & 0.827 \\
\hline $\mathrm{pH}$ & 6.5 & 5.5 \\
\hline Colour /Odour & Colourless / Odourless & Colourless / Odourless \\
\hline
\end{tabular}

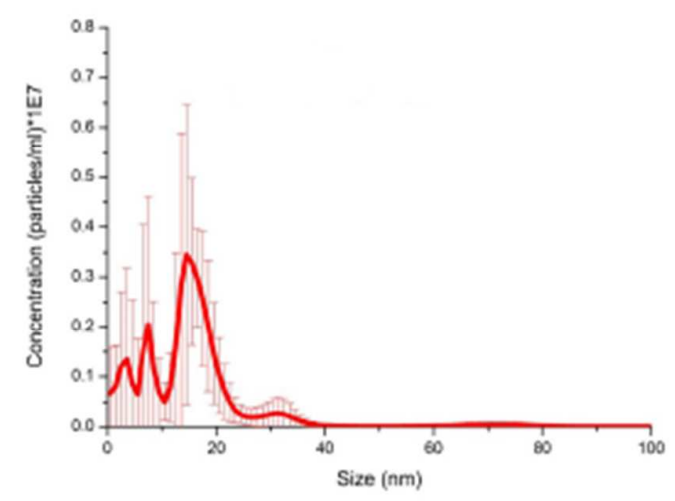

Figure 1: Particle size distribution of the nanodiamonds as received

3. Results and Discussion

A) Tribological performance under low load schemes - on the conveyor belts

An industrial-size stainless steel belt conveyor was used for testing friction and scaring (or scuffing) on the bottom of three types of beverage packaging (aluminium cans, glass bottles and PET bottles) typically found in the bottling and filling food industries. The belt travelled at a speed of $20 \mathrm{~m} / \mathrm{min}$ and the tests were run for $60 \mathrm{~min}$ (Figure 2). A test was run without any lubrication (labelled as 'blank'). When lubricants were present, these were deposited onto the conveyor belts in 'dry-regime' conditions on top of the chain on the wear strips. The lubricants tested were mineral base oil (labelled 'Min'), nanolubricant comprising the dispersion of nanodiamonds $30 \mathrm{~nm}$ in the mineral oil (Min30) and nanolubricant comprising the dispersion of the nanodiamonds $30 \mathrm{~nm}$ in the PAO oil (PAO30). Results from the friction using only base oil PAO are similar to those of mineral only and therefore not shown. 


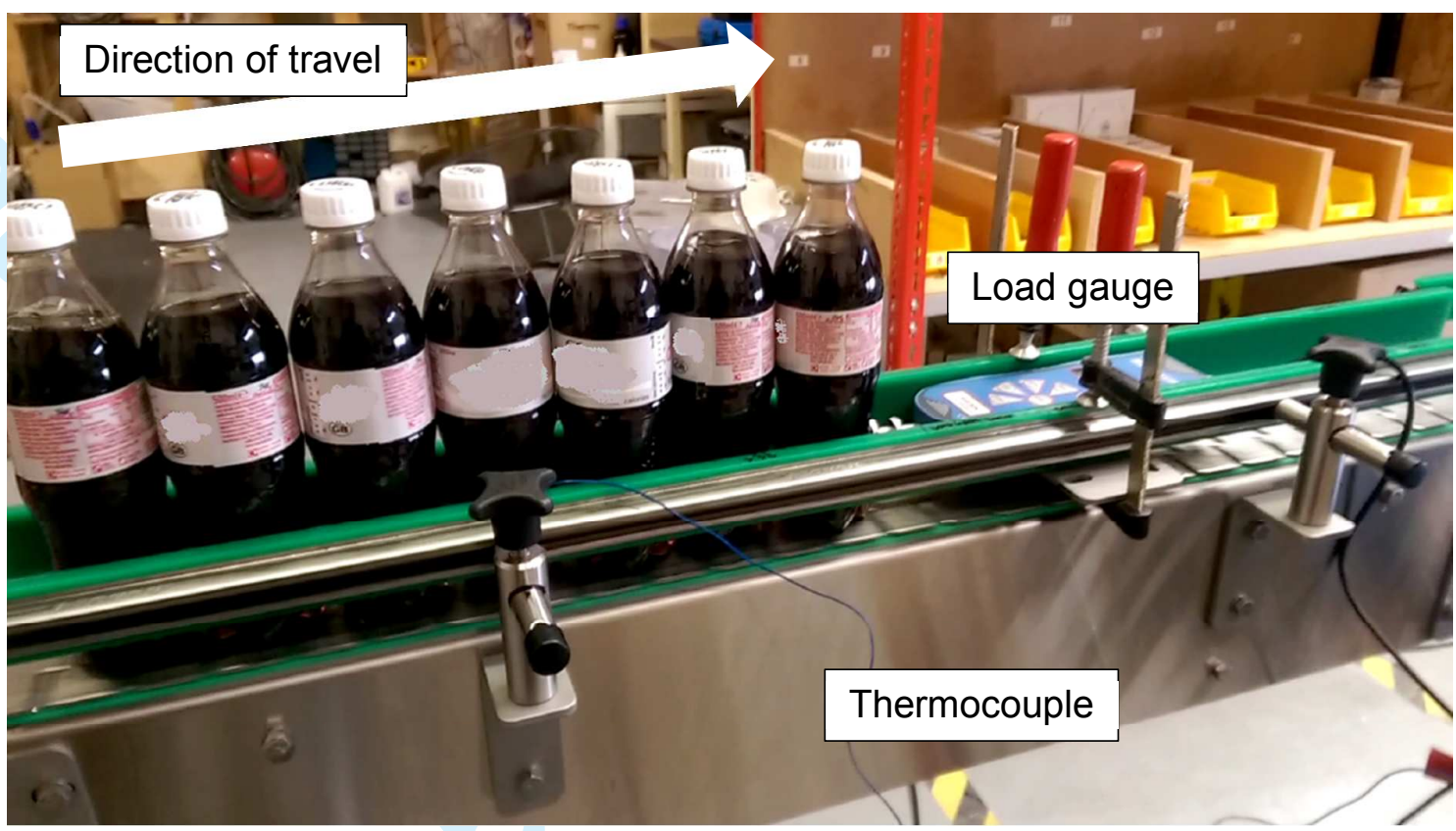

Figure 2: Experimental set up for the low load scheme (on the conveyor belt)
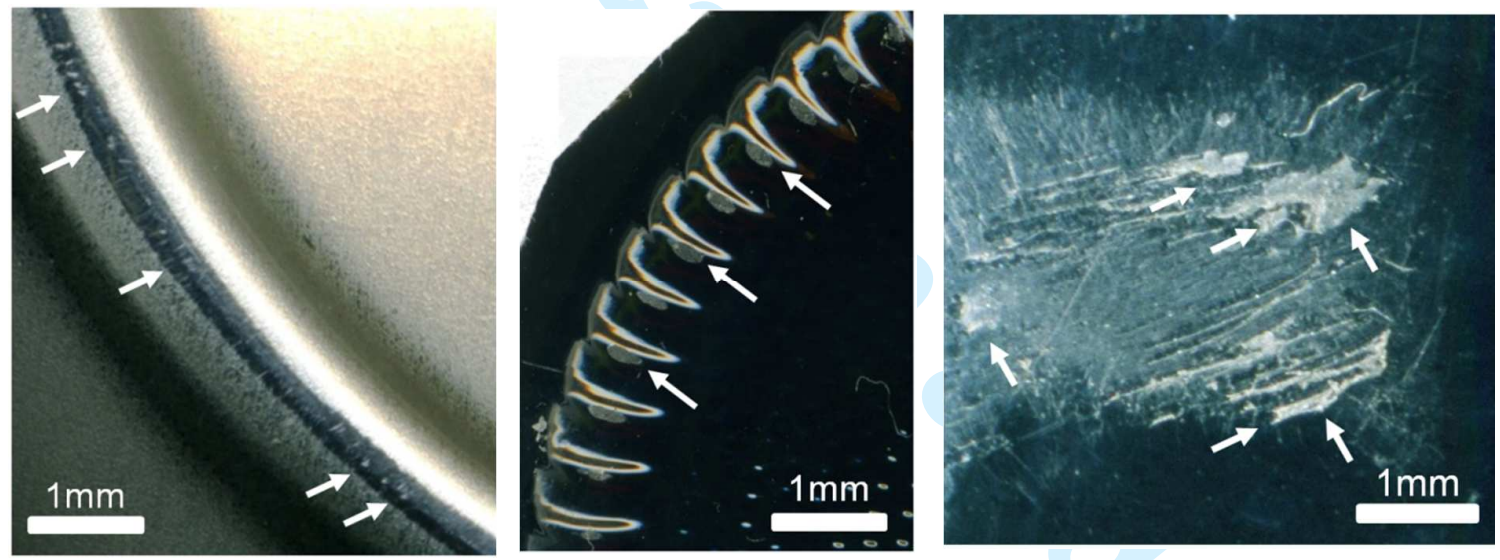

Figure 3: Representative scars and scuffing on packages used on the conveyors: (left) aluminium cans, (middle) glass bottles, (right) PET bottles

Boundary was the regime of lubrication observed and it remained stable throughout the duration of the friction test in all cases. Examination to the bottom of the packages revealed scratches due to the abrasion (Figure 3). The coefficient of friction (COF) for each of the packages as a function of time and the wear scar area for each of the lubricating fluids including the 'blank' are plotted in Figure 4 and Figure 5. The results of the measurements are summarised in Table 2. As it can be seen in Figure 4, maximum COF values (within the range 0.16-0.25) were reached when there was no lubricating fluid present (i.e., in 'blank' conditions). In the presence of lubrication, COF values were reduced generally for all the beverage packages, as per Table 2 . The COF reduction is $35 \%$ in the aluminium cans, $\sim 27 \%$ in the glass bottles, and $63 \%$ in the PET bottles. The wear print decreases $\sim 43 \%$ in 
the glass bottles. The aluminium cans with nanolubricant fabricated using PAO oil and $30 \mathrm{~nm}$ nanodiamond presents the most remarkable drop $(52 \%)$ compared to the use of the plain oil (17\%). This effect is also observed in the PET bottles, with a better performance of the nanodiamond-loaded oils compared to the plain oil. It can be hypothesed therefore that the nanoparticles are agglomerates that allow higher probability for the 'ball bearing' effect to develop between the two surfaces in contact, in that way protecting from solid-to-solid abrasion. Similar reduction values for the COF and wear scars have been reported by other authors working in the same oilnanodiamond system [48-50], the paraffin-nanodiamond system [25], and an oil-non nanodiamond system [18].

It is worth noting the difference between the aluminium cans and the PET bottles: the latter ones exhibit lower COFs. Further investigation on the scars and scuffing on the bottles revealed a plastic deformation on the materials (i.e. pilling) along with heavy scratches which could have contributed to lowering the friction between the bottles (soft material) against the conveyor belt (harder material) (Figure 3, right, see arrows). This mixed abrasive-plastic deformation mechanism has been observed in other studies [51]. On the other hand, this event cannot be observed on the aluminium cans, whose worn area is characterised by linear scratches only (i.e. hard on hard materials) (Figure 3, left). 


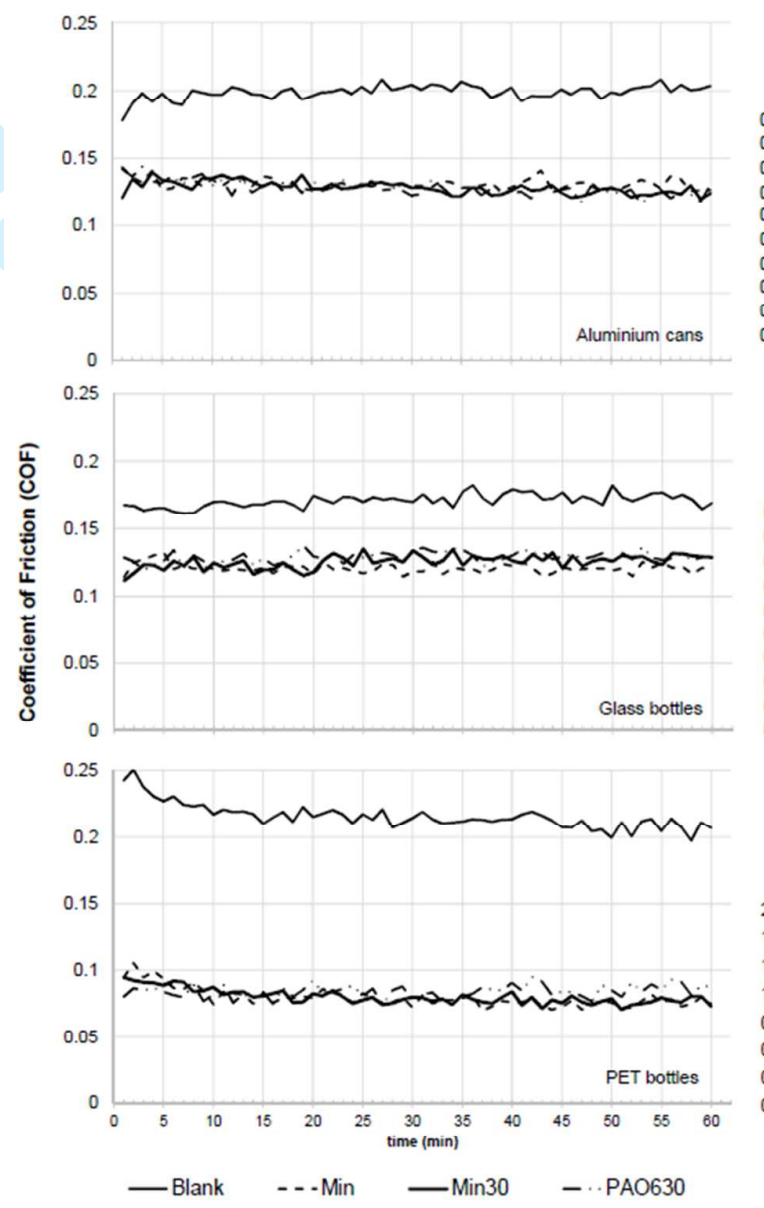

Figure 4: COF values for low load scheme
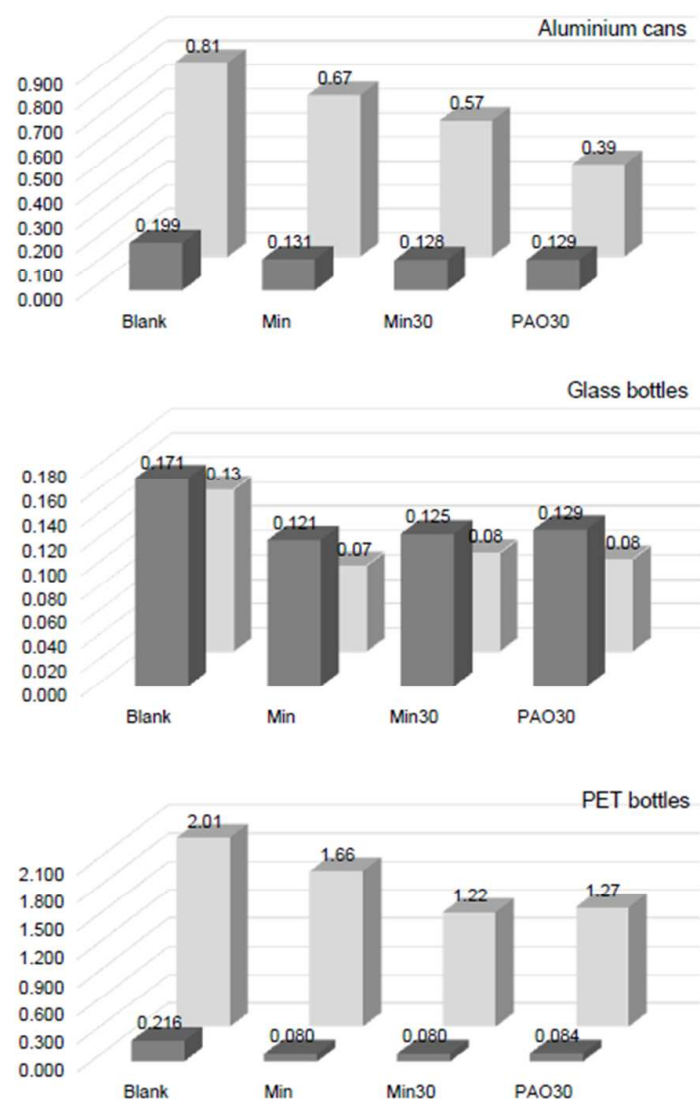

nCOF (average)

Table 2: Coefficient of friction and wear scar area values for each of the packages when using the lubricating fluids on the conveyors

\begin{tabular}{|c|c|c|c|c|c|c|}
\hline & \multicolumn{2}{|c|}{ Aluminium cans } & \multicolumn{2}{|c|}{ Glass bottles } & \multicolumn{2}{|c|}{ PET bottles } \\
\hline Mass (average) & $0.530 \mathrm{~kg}$ & & $1.131 \mathrm{~kg}$ & & $0.543 \mathrm{~kg}$ & \\
\hline Dimensions & $6.63 \mathrm{~cm}$ diame & & $8.2 \mathrm{~cm}$ diamete & & $6.76 \mathrm{~cm}$ diame & \\
\hline $\begin{array}{l}\text { Contact } \\
\text { surface }\end{array}$ & $\begin{array}{l}\text { Circular lip, O } \\
4.7 \mathrm{~cm}\end{array}$ & $5.26 \mathrm{~cm}, \mathrm{ID}$ & $\begin{array}{l}\text { Circular lip, O } \\
7.1 \mathrm{~cm}\end{array}$ & $8.2 \mathrm{~cm}, \mathrm{ID}$ & $\begin{array}{l}\text { Pentalobe bas } \\
0.71 \mathrm{~cm} \times 0.8 \mathrm{cn}\end{array}$ & e, each lobe \\
\hline & $\begin{array}{l}\text { COF(std) } \\
(\Delta \%)\end{array}$ & $\begin{array}{l}\text { Wear, } \mathrm{cm}^{2} \\
\text { (std) }(\Delta \%)\end{array}$ & $\begin{array}{l}\text { COF(std) } \\
(\Delta \%)\end{array}$ & $\begin{array}{l}\text { Wear, } \mathrm{cm}^{2} \\
\text { (std) }(\Delta \%)\end{array}$ & $\begin{array}{l}\text { COF(std) } \\
(\Delta \%)\end{array}$ & $\begin{array}{l}\text { Wear, cm } \\
\text { (std) }(\Delta \%)\end{array}$ \\
\hline Blank & $\begin{array}{l}0.199(0.009) \\
(-)\end{array}$ & $\begin{array}{l}0.81(0.12) \\
(-)\end{array}$ & $\begin{array}{l}0.171(0.013) \\
(-)\end{array}$ & $\begin{array}{l}0.13(0.03) \\
(-)\end{array}$ & $\begin{array}{l}0.216(0.016) \\
(-)\end{array}$ & $\begin{array}{l}2.01(0.58) \\
(-)\end{array}$ \\
\hline Min & $\begin{array}{l}0.131(0.014) \\
(-34 \%)\end{array}$ & $\begin{array}{l}0.67(0.13) \\
(-17 \%)\end{array}$ & $\begin{array}{l}0.121(0.011) \\
(-29 \%)\end{array}$ & $\begin{array}{l}0.07(0.02) \\
(-47 \%)\end{array}$ & $\begin{array}{l}0.080(0.010) \\
(-63 \%)\end{array}$ & $\begin{array}{l}1.66(0.38) \\
(-18 \%)\end{array}$ \\
\hline Min30 & $\begin{array}{l}0.128(0.014) \\
(-35 \%)\end{array}$ & $\begin{array}{l}0.57(0.05) \\
(-30 \%)\end{array}$ & $\begin{array}{l}0.125(0.022) \\
(-27 \%)\end{array}$ & $\begin{array}{l}0.08(0.01) \\
(-39 \%)\end{array}$ & $\begin{array}{l}0.080(0.014) \\
(-63 \%)\end{array}$ & $\begin{array}{l}1.22(0.56) \\
(-40 \%)\end{array}$ \\
\hline PAO30 & $\begin{array}{l}0.129(0.016) \\
(-35 \%)\end{array}$ & $\begin{array}{l}0.39(0.10) \\
(-52 \%)\end{array}$ & $\begin{array}{l}0.129(0.014) \\
(-25 \%)\end{array}$ & $\begin{array}{l}0.08(0.02) \\
(-43 \%)\end{array}$ & $\begin{array}{l}0.084(0.013) \\
(-61 \%)\end{array}$ & $\begin{array}{l}1.27(0.29) \\
(-37 \%)\end{array}$ \\
\hline
\end{tabular}


B) Tribological performance under high load schemes

The load-carrying and anti-wear properties of the nanolubricants in high pressure conditions were compared to those of the base oil without the particles. As per ASTM D2783, three chrome alloy steel balls (of $12.7 \mathrm{~mm}$ diam, with a Rockwell C hardness in the range 64-66 and a surface roughness grade $25 \mathrm{EP}$ (extra polish)) were locked in a tribometer test cup. The under-test lubricant was poured over them. A fourth steel ball was held in place in a rotating clamp and placed on top of the 3 balls. It was then made to spin at $1,760 \mathrm{rpm}$ and subjected to a $10 \mathrm{sec}$ long series at increasing loads until welding of the balls occurred. The load was recorded. This test allowed the finding of the load wear index (LWI) which quantifies the wear protection at high loads, and of the weld point, i.e. lowest applied load at which sliding surfaces of the balls seize and therefore weld. The results for LWI as a function of the lubricant used can be shown in Figure 6. No significant difference was exhibited for the four lubricating fluids. Similarly, a 4 ball tribometer was used for measuring wear preventing characteristics of a lubricant as per ASTM D4172. Three new steel balls (features as above) were locked in the test cup and a fourth ball placed on top of the cavity formed by the 3 clamped balls for 3point contact. At a lubricant temperature of $75^{\circ} \mathrm{C}$ the top ball was rotated at $1,200 \mathrm{rpm}$ while applying a force of $392 \mathrm{~N}$. After $60 \mathrm{~min}$ the top ball was discarded, the 3 remaining balls cleaned and inspected for wear damage under optical microscope, and the wear scar diameter (WSD) measured. Results are shown in Figure 7. Both the ASTM D2783 and the ASTM D4172 tests were performed at standard ambient conditions ( $1 \mathrm{~atm}, 25 \mathrm{C}, 45 \% \mathrm{RH}$ )

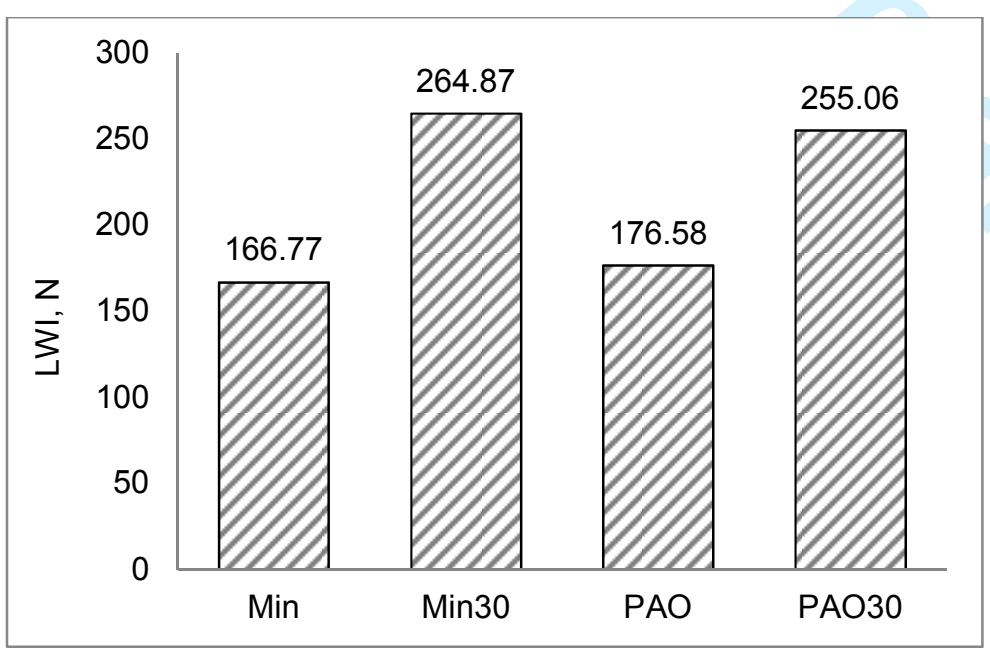

Figure 6: Results for the ASTM D2783 extreme pressure tests 


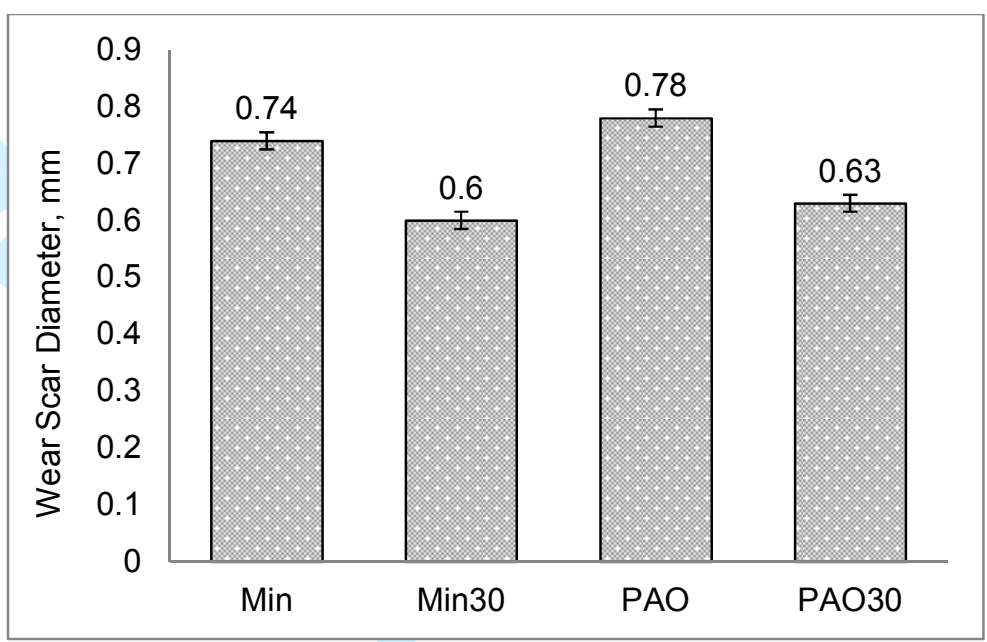

Figure 7: Results for the ASTM D4172 on wear preventing characteristics tests

It can be extracted from the LWI results that the nanolubricants present an increment in anti-wear properties (58.8\% and $44.4 \%$ ) with respect to the base oils alone (mineral and PAO). This result is consistent with results obtained on other oilnanoparticle systems $[15,18]$. A large value of LWI indicates a larger ability of the lubricant to prevent wear at applied loads. The four lubricants seized at $1236.06 \mathrm{~N}$, being that their weld point. This suggests that the nanodiamonds do not display significant load-carrying improvements when compared to the base oils. In the results from the WSDs the nanolubricants present a 19\% smaller diameter of wear scar with respect to the plain oil, which indicates a significant anti-wear protection improvement provided by the nanoparticles.

\section{Conclusions}

In this study the tribological performance of a nanolubricant prepared with nanodiamonds dispersed in commercial oils (mineral and polyalphaolefin) was studied. As a lubricant to be used on beverage conveyor systems and in contact with food packages, a factory-sized set-up was considered for the friction and wear tests under low load conditions, in accordance with the conditions in industry. The characterisation of load-bearing, anti-friction and anti-wear (e.g. scratching or scuffing) capacity of the lubricant at large pressures and high loads was also of interest since the purpose is to develop a versatile lubricant that can be used also on mechanical machinery within the factory.

- With the prolonged low pressure friction process, wear scar was reduced in the presence of the nanolubricant comprising nanodiamonds of $<30 \mathrm{~nm}$ dispersed in the base oils.

- The predominant regime of lubrication was boundary film and the solid-solid friction mechanisms observed were abrasion (cans and glass bottles) and plastic deformation (PET bottles). 
- The results at high pressure conditions show that the friction occurred in the presence of nanolubricating fluids was lower than that of the pure oils, which suggests that the nanodiamonds have good friction-reduction properties.

Acknowledgements

This work has been supported by a grant from Innovate UK (KTP 9434), United Kingdom.

References

1. Rapoport, L., et al., Hollow nanoparticles of WS2 as potential solid-state lubricants. Nature, 1997. 387(6635): p. 791-793.

2. Scharf, T.W. and S.V. Prasad, Solid lubricants: a review. Journal of Materials Science, 2013. 48(2): p. 511-531.

3. Valencia, S.A.S., et al., Lubricant for conveying containers, WO2007094980 A2, WO2007094980 A2, 2007.

4. Grosse, B.W., et al., Anti-friction lubricants containing fluorine, WO 2001018157 A2, 2001.

5. Chamblee, K.W., et al., Conveyor lubricants including emulsions and methods employing them, PCT/IB2011/054184, 2012.

6. Li, M., et al., Antimicrobial lubricants useful for lubricating containers, such as beverage containers, and conveyors therefor, PCT/US2000/017525, WO2001023504 A1, 2001.

7. McSherry, D.D. and G.J. Wei, Fatty amide ethoxylate phosphate ester conveyor lubricant, US5925601 A, WO2000022073 A1, 1999.

8. Despo, A.D., Lubricant for transport of P.E.T. containers, US5391308 A, 1995.

9. Scheld, J.L., PTFE oil coating composition, US 5160646 A, 1992.

10. Findik, F., Latest progress on tribological properties of industrial materials. Materials \& Design, 2014. 57: p. 218-244.

11. Wang, J., et al., Tribological properties of water - soluble TiO2 nanoparticles as additives in water. Industrial Lubrication and Tribology, 2010. 62(5): p. 292297.

12. Padgurskas, J., et al., Development and modification of $\mathrm{Fe}$ and $\mathrm{FeCu}$ nanoparticles and tribological analysis of the lubricants with nano suspensions. Industrial Lubrication and Tribology, 2012. 64(5): p. 253-257.

13. Tarasov, S., et al., Study of friction reduction by nanocopper additives to motor oil. Wear, 2002. 252(1-2): p. 63-69.

14. Hu, Z.S. and J.X. Dong, Study on antiwear and reducing friction additive of nanometer titanium borate. Wear, 1998. 216(1): p. 87-91.

15. Zhang, Y., et al., Synthesis and tribological properties of oil-soluble copper nanoparticles as environmentally friendly lubricating oil additives. Industrial Lubrication and Tribology, 2015. 67(3): p. 227-232.

16. Kumar Dubey, M., J. Bijwe, and S.S.V. Ramakumar, PTFE based nanolubricants. Wear, 2013. 306(1-2): p. 80-88.

17. Hu, Z.S. and J.X. Dong, Study on antiwear and reducing friction additive of nanometer titanium oxide. Wear, 1998. 216(1): p. 92-96. 
18. Huang, Y., et al., Preparation and tribological properties of surface-modified calcium borate nanoparticles as additive in lubricating oil. Industrial Lubrication and Tribology, 2014. 66(1): p. 143-150.

19. Thakre, A.A. and A. Thakur, Study of behaviour of aluminium oxide nanoparticles suspended in SAE20W40 oil under extreme pressure Iubrication. Industrial Lubrication and Tribology, 2015. 67(4): p. 328-335.

20. Zhang, M., X. Wang, and W. Liu, Tribological behavior of LaF3 nanoparticles as additives in poly - alpha - olefin. Industrial Lubrication and Tribology, 2013. 65(4): p. 226-235.

21. Hernández Battez, A., et al., $\mathrm{CuO}, \mathrm{ZrO} 2$ and $\mathrm{ZnO}$ nanoparticles as antiwear additive in oil lubricants. Wear, 2008. 265(3-4): p. 422-428.

22. Maliar, T., et al., Tribological behaviour of mineral and rapeseed oils containing iron particles. Industrial Lubrication and Tribology, 2015. 67(4): p. 308-314.

23. Biresaw, G. and S.M. Erhan, Solid lubricant formulations containing starchsoybean oil composites. Journal of the American Oil Chemists' Society, 2002. 79(3): p. 291-296.

24. Zhou, X., et al., Tribological properties of Cyanex 301 - modified MoS2 nano - sized hollow spheres in liquid paraffin. Industrial Lubrication and Tribology, 2008. 60(3): p. 147-152.

25. Peng, D.X., et al., Tribological properties of diamond and SiO2 nanoparticles added in paraffin. Tribology International, 2009. 42(6): p. 911-917.

26. Zhou, J., et al., Study on the structure and tribological properties of surfacemodified Cu nanoparticles. Materials Research Bulletin, 1999. 34(9): p. 13611367.

27. Zhang, Z.J., J. Zhang, and Q.J. Xue, Synthesis and Characterization of a Molybdenum Disulfide Nanocluster. The Journal of Physical Chemistry, 1994. 98(49): p. 12973-12977.

28. Tang, Z. and S. Li, A review of recent developments of friction modifiers for liquid lubricants (2007-present). Current Opinion in Solid State and Materials Science, 2014. 18(3): p. 119-139.

29. Yamamoto, Y., et al., Frictional characteristics of molybdenum dithiophosphates. Wear, 1986. 112(1): p. 79-87.

30. Lee, K., et al., Understanding the Role of Nanoparticles in Nano-oil Lubrication. Tribology Letters, 2009. 35(2): p. 127-131.

31. Wu, Y.Y., W.C. Tsui, and T.C. Liu, Experimental analysis of tribological properties of lubricating oils with nanoparticle additives. Wear, 2007. 262(7-8): p. 819-825.

32. Chiñas-Castillo, F. and H.A. Spikes, Mechanism of Action of Colloidal Solid Dispersions. Journal of Tribology, 2003. 125(3): p. 552-557.

33. Tevet, O., et al., Friction mechanism of individual multilayered nanoparticles. Proceedings of the National Academy of Sciences, 2011. 108(50): p. 1990119906.

34. Huang, H.D., et al., An investigation on tribological properties of graphite nanosheets as oil additive. Wear, 2006. 261(2): p. 140-144.

35. Ping, L., et al., Preparation and tribological properties of complex nanoparticle styrene/calcium borate with core-shell structure. Industrial Lubrication and Tribology, 2014. 66(4): p. 525-532. 
36. Xue, Q., W. Liu, and Z. Zhang, Friction and wear properties of a surfacemodified TiO2 nanoparticle as an additive in liquid paraffin. Wear, 1997. 213(1-2): p. 29-32.

37. Hu, Z.S., et al., Preparation and tribological properties of nanometer magnesium borate as lubricating oil additive. Wear, 2002. 252(5-6): p. 370374.

38. Gibson, N., et al., Colloidal stability of modified nanodiamond particles. Diamond and Related Materials, 2009. 18(4): p. 620-626.

39. Tao, X., Z. Jiazheng, and X. Kang, The ball-bearing effect of diamond nanoparticles as an oil additive. Journal of Physics D: Applied Physics, 1996. 29(11): p. 2932.

40. Chu, H.Y., W.C. Hsu, and J.F. Lin, The anti-scuffing performance of diamond nano-particles as an oil additive. Wear, 2010. 268(7-8): p. 960-967.

41. Liang, Y., M. Ozawa, and A. Krueger, A General Procedure to Functionalize Agglomerating Nanoparticles Demonstrated on Nanodiamond. ACS Nano, 2009. 3(8): p. 2288-2296.

42. Pentecost, A., et al., Deaggregation of Nanodiamond Powders Using Saltand Sugar-Assisted Milling. ACS Applied Materials \& Interfaces, 2010. 2(11): p. 3289-3294.

43. Ozawa, M., et al., Preparation and Behavior of Brownish, Clear Nanodiamond Colloids. Advanced Materials, 2007. 19(9): p. 1201-1206.

44. Yu. Dolmatov, V., Detonation synthesis ultradispersed diamonds: properties and applications. Russian Chemical Reviews, 2001. 70(7): p. 607-626.

45. Dolmatov, V.Y., Detonation nanodiamonds in oils and lubricants. Journal of Superhard Materials, 2010. 32(1): p. 14-20.

46. Mochalin, V.N., et al., The properties and applications of nanodiamonds. Nat Nano, 2012. 7(1): p. 11-23.

47. Hsin, Y.L., et al., In situ de-agglomeration and surface functionalization of detonation nanodiamond, with the polymer used as an additive in lubricant oil. Journal of Materials Chemistry, 2011. 21(35): p. 13213-13222.

48. Nunn, N., et al., Tribological properties of polyalphaolefin oil modified with nanocarbon additives. Diamond and Related Materials, 2015. 54: p. 97-102.

49. Ivanov, M.G., L.E. Deev, and O.A. Shenderova, Lubricant and synergistic additive formulation, US 20120122743 A1, WO 2011011714 A1, , 2011.

50. Ivanov, M., et al., Nanodiamond-based oil lubricants on steel-steel and stainless steel-hard alloy high load contact: Investigation of friction surfaces. Nanosystems: Physics, Chemistry, Mathematics, 2014. 5(1): p. 160-166.

51. Aydin, M. and F. Findik, Wear properties of magnesium matrix composites reinforced with SiO2 particles. Industrial Lubrication and Tribology, 2010. 62(4): p. 232-237. 
Table 1: Rheological properties of the base oils

\begin{tabular}{|c|c|c|}
\hline & Mineral oil & PAO oil \\
\hline Commercial name & Kristol M24 & SpectraSyn 6 \\
\hline $\begin{array}{l}\text { Kinematic viscosity } \\
\left(\mathrm{mm}^{2} / \mathrm{s}\right) 40^{\circ} \mathrm{C}\end{array}$ & 36.0 & 30.0 \\
\hline Pour point $\left({ }^{\circ} \mathrm{C}\right)$ & -6 & -57 \\
\hline Flash point $\left({ }^{\circ} \mathrm{C}\right)$ & 180 & 249 \\
\hline Specific gravity (at $15^{\circ} \mathrm{C}$ ) & 0.859 & 0.827 \\
\hline pH & 6.5 & 5.5 \\
\hline Colour IOdour & Colourless / Odourless & Colourless / Odourless \\
\hline
\end{tabular}

Table 2: Coefficient of friction and wear scar area values for each of the packages when using the lubricating fluids on the conveyors

\begin{tabular}{|c|c|c|c|c|c|c|}
\hline & \multicolumn{2}{|c|}{ Aluminium cans } & \multicolumn{2}{|c|}{ Glass bottles } & \multicolumn{2}{|c|}{ PET bottles } \\
\hline Mass (average) & $0.530 \mathrm{~kg}$ & & $1.131 \mathrm{~kg}$ & & $0.543 \mathrm{~kg}$ & \\
\hline Dimensions & $6.63 \mathrm{~cm}$ diame & & $8.2 \mathrm{~cm}$ diamet & & $6.76 \mathrm{~cm}$ diame & \\
\hline $\begin{array}{l}\text { Contact } \\
\text { surface }\end{array}$ & $\begin{array}{l}\text { Circular lip, O } \\
4.7 \mathrm{~cm}\end{array}$ & $5.26 \mathrm{~cm}, \mathrm{ID}$ & $\begin{array}{l}\text { Circular lip, O } \\
7.1 \mathrm{~cm}\end{array}$ & $8.2 \mathrm{~cm}, \mathrm{ID}$ & $\begin{array}{l}\text { Pentalobe bas } \\
0.71 \mathrm{~cm} \times 0.8 \mathrm{cn}\end{array}$ & , each lobe \\
\hline & $\begin{array}{l}\text { COF(std) } \\
(\Delta \%)\end{array}$ & $\begin{array}{l}\text { Wear, } \mathbf{c m}^{2} \\
\text { (std) }(\Delta \%)\end{array}$ & $\begin{array}{l}\text { COF(std) } \\
(\Delta \%)\end{array}$ & $\begin{array}{l}\text { Wear, } \mathrm{cm}^{2} \\
\text { (std) }(\Delta \%)\end{array}$ & $\begin{array}{l}\text { COF(std) } \\
(\Delta \%)\end{array}$ & $\begin{array}{l}\text { Wear, cm } \\
\text { (std) }(\Delta \%)\end{array}$ \\
\hline Blank & $\begin{array}{l}0.199(0.009) \\
(-)\end{array}$ & $\begin{array}{l}0.81(0.12) \\
(-)\end{array}$ & $\begin{array}{l}0.171(0.013) \\
(-)\end{array}$ & $\begin{array}{l}0.13(0.03) \\
(-)\end{array}$ & $\begin{array}{l}0.216(0.016) \\
(-)\end{array}$ & $\begin{array}{l}2.01(0.58) \\
(-)\end{array}$ \\
\hline Min & $\begin{array}{l}0.131(0.014) \\
(-34 \%)\end{array}$ & $\begin{array}{l}0.67(0.13) \\
(-17 \%)\end{array}$ & $\begin{array}{l}0.121(0.011) \\
(-29 \%)\end{array}$ & $\begin{array}{l}0.07(0.02) \\
(-47 \%)\end{array}$ & $\begin{array}{l}0.080(0.010) \\
(-63 \%)\end{array}$ & $\begin{array}{l}1.66(0.38) \\
(-18 \%)\end{array}$ \\
\hline Min30 & $\begin{array}{l}0.128(0.014) \\
(-35 \%)\end{array}$ & $\begin{array}{l}0.57(0.05) \\
(-30 \%)\end{array}$ & $\begin{array}{l}0.125(0.022) \\
(-27 \%)\end{array}$ & $\begin{array}{l}0.08(0.01) \\
(-39 \%)\end{array}$ & $\begin{array}{l}0.080(0.014) \\
(-63 \%)\end{array}$ & $\begin{array}{l}1.22(0.56) \\
(-40 \%)\end{array}$ \\
\hline PAO30 & $\begin{array}{l}0.129(0.016) \\
(-35 \%)\end{array}$ & $\begin{array}{l}0.39(0.10) \\
(-52 \%)\end{array}$ & $\begin{array}{l}0.129(0.014) \\
(-25 \%)\end{array}$ & $\begin{array}{l}0.08(0.02) \\
(-43 \%)\end{array}$ & $\begin{array}{l}0.084(0.013) \\
(-61 \%)\end{array}$ & $\begin{array}{l}1.27(0.29) \\
(-37 \%)\end{array}$ \\
\hline
\end{tabular}




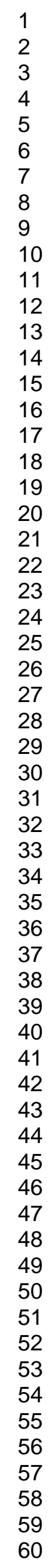

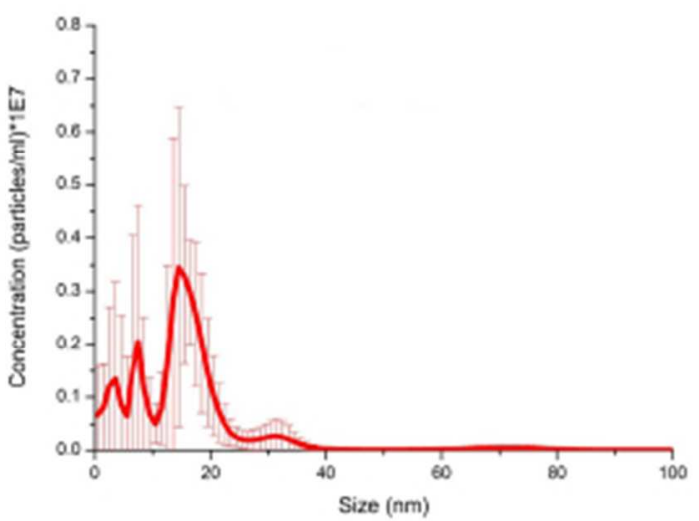

$78 \times 59 \mathrm{~mm}(96 \times 96 \mathrm{DPI})$ 


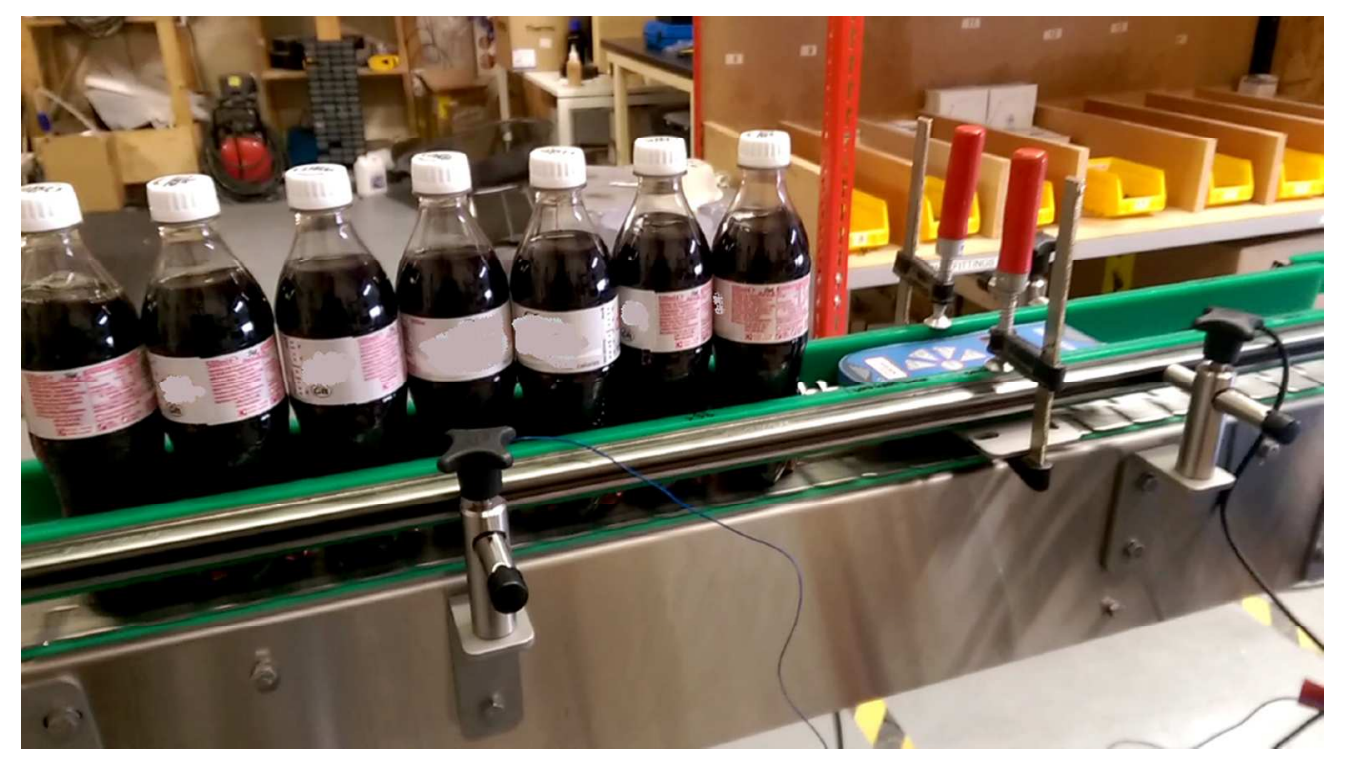




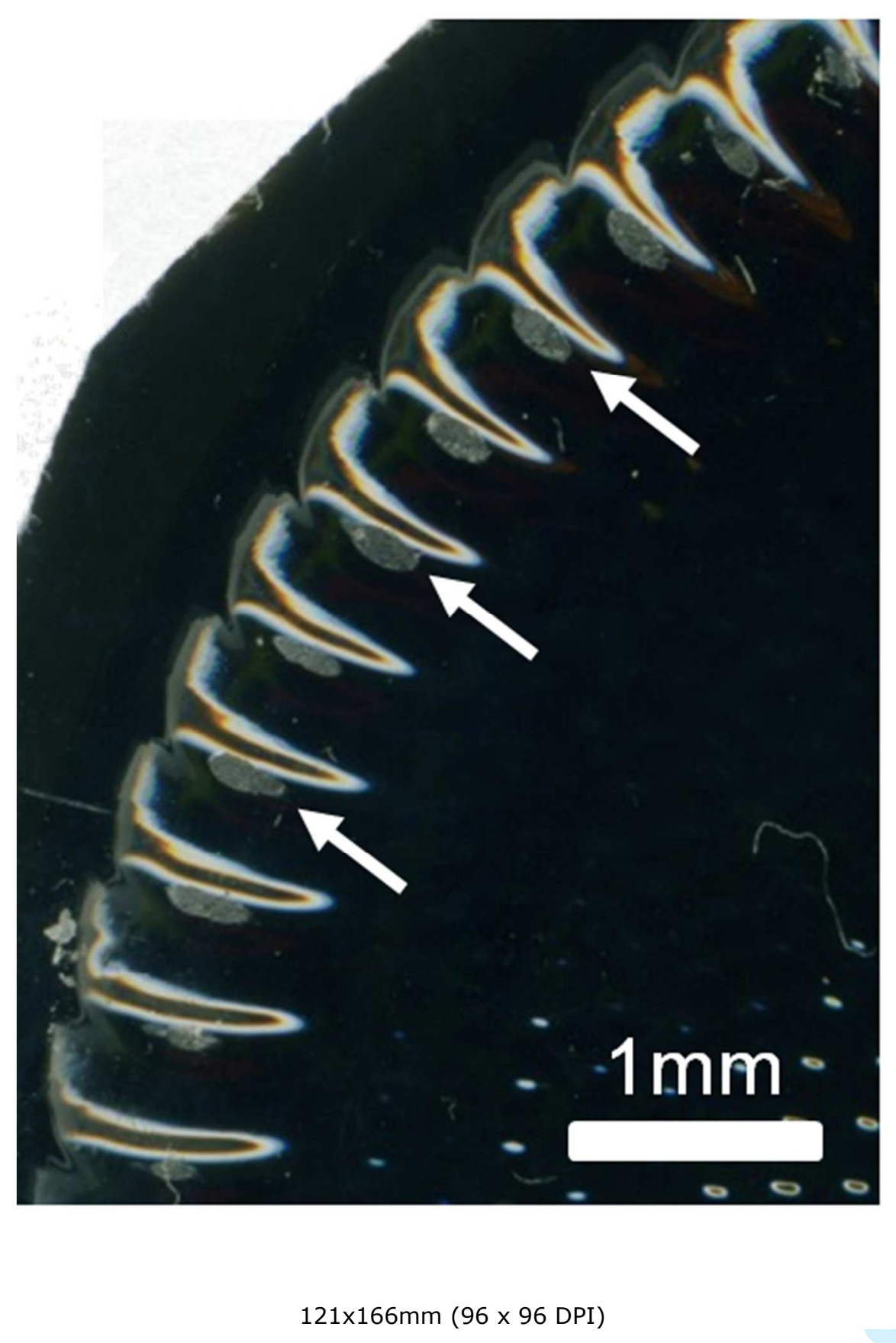




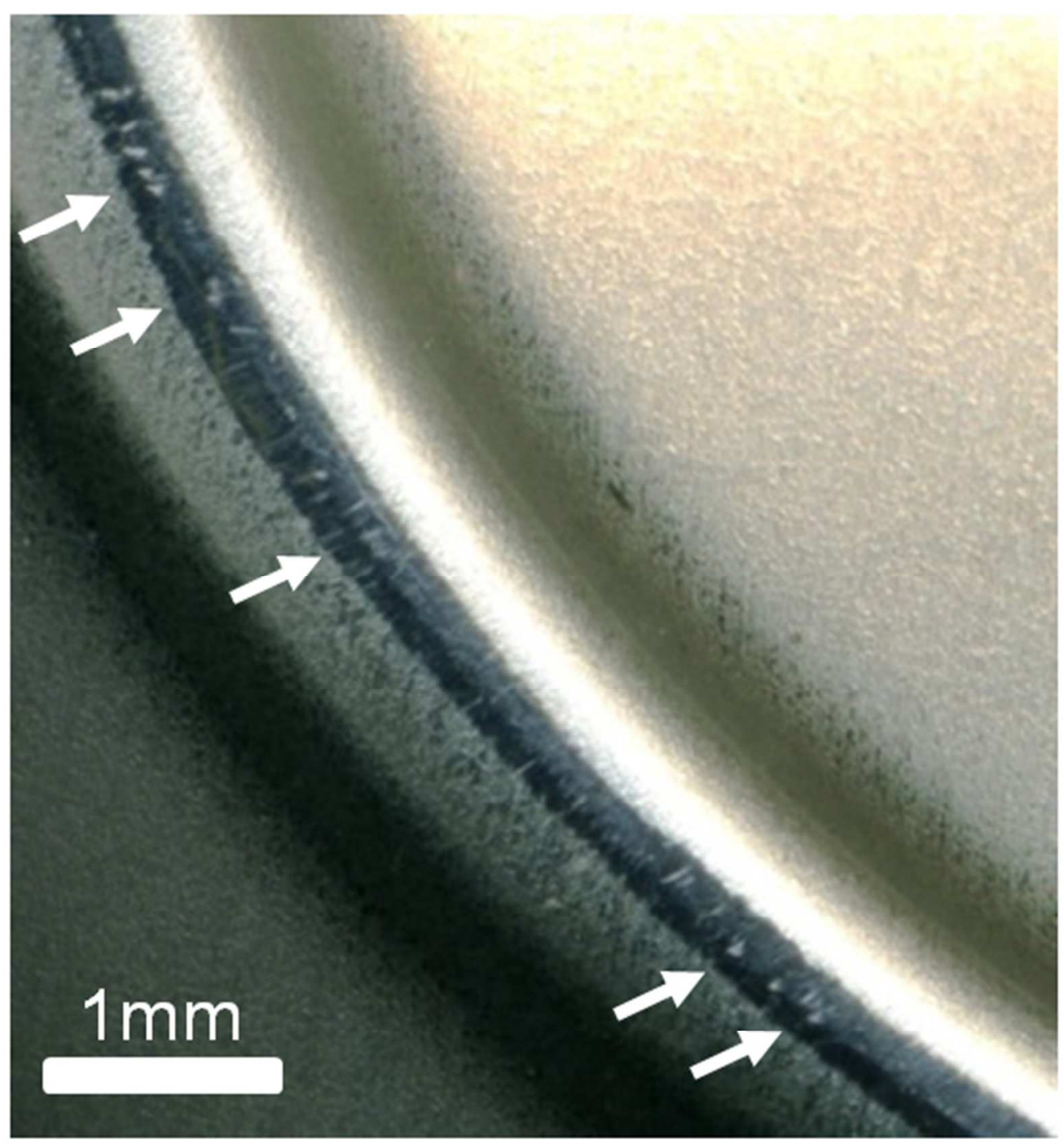

$146 \times 156 \mathrm{~mm}(96 \times 96 \mathrm{DPI})$ 


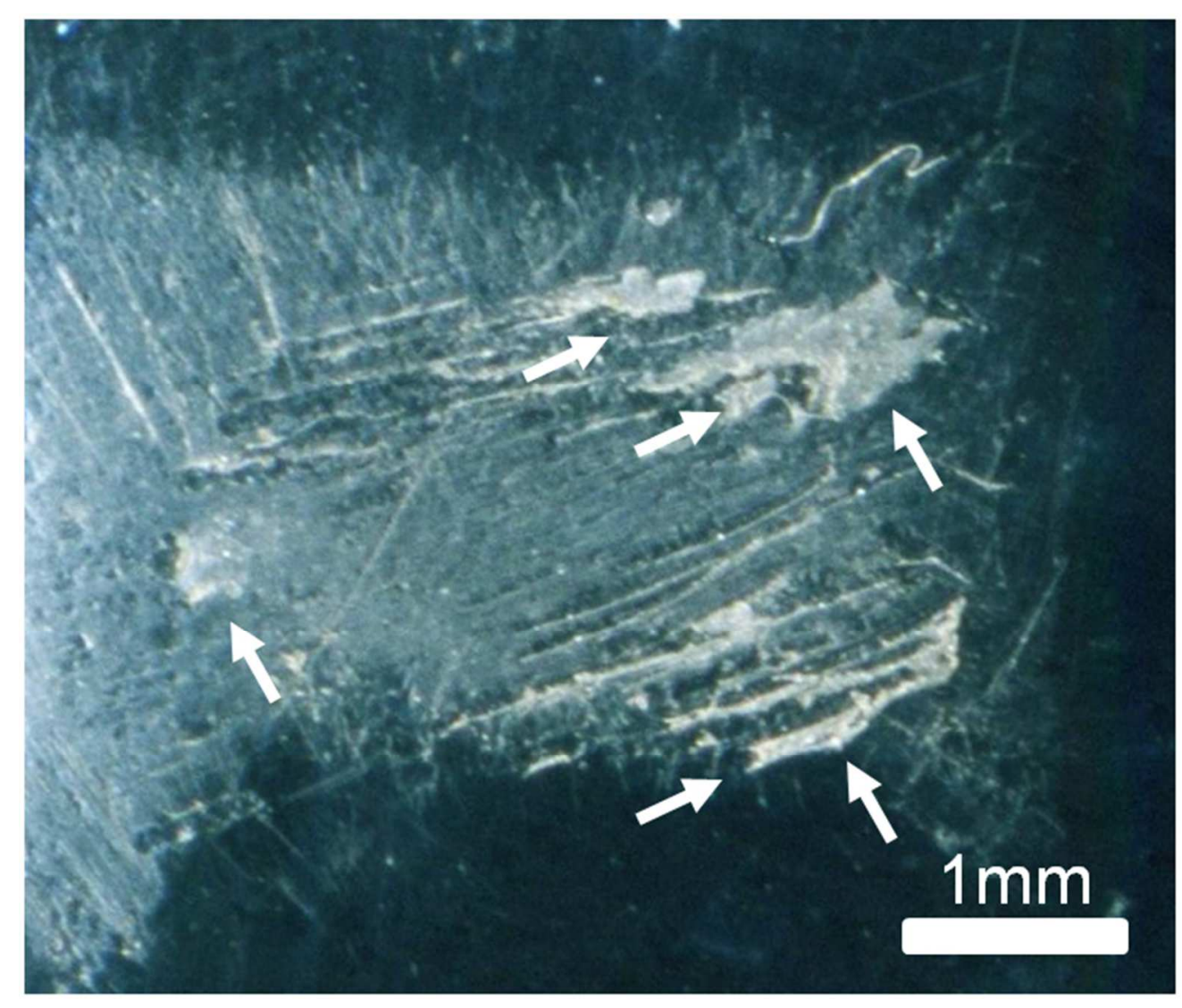

$195 \times 166 \mathrm{~mm}(96 \times 96 \mathrm{DPI})$

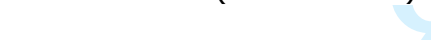




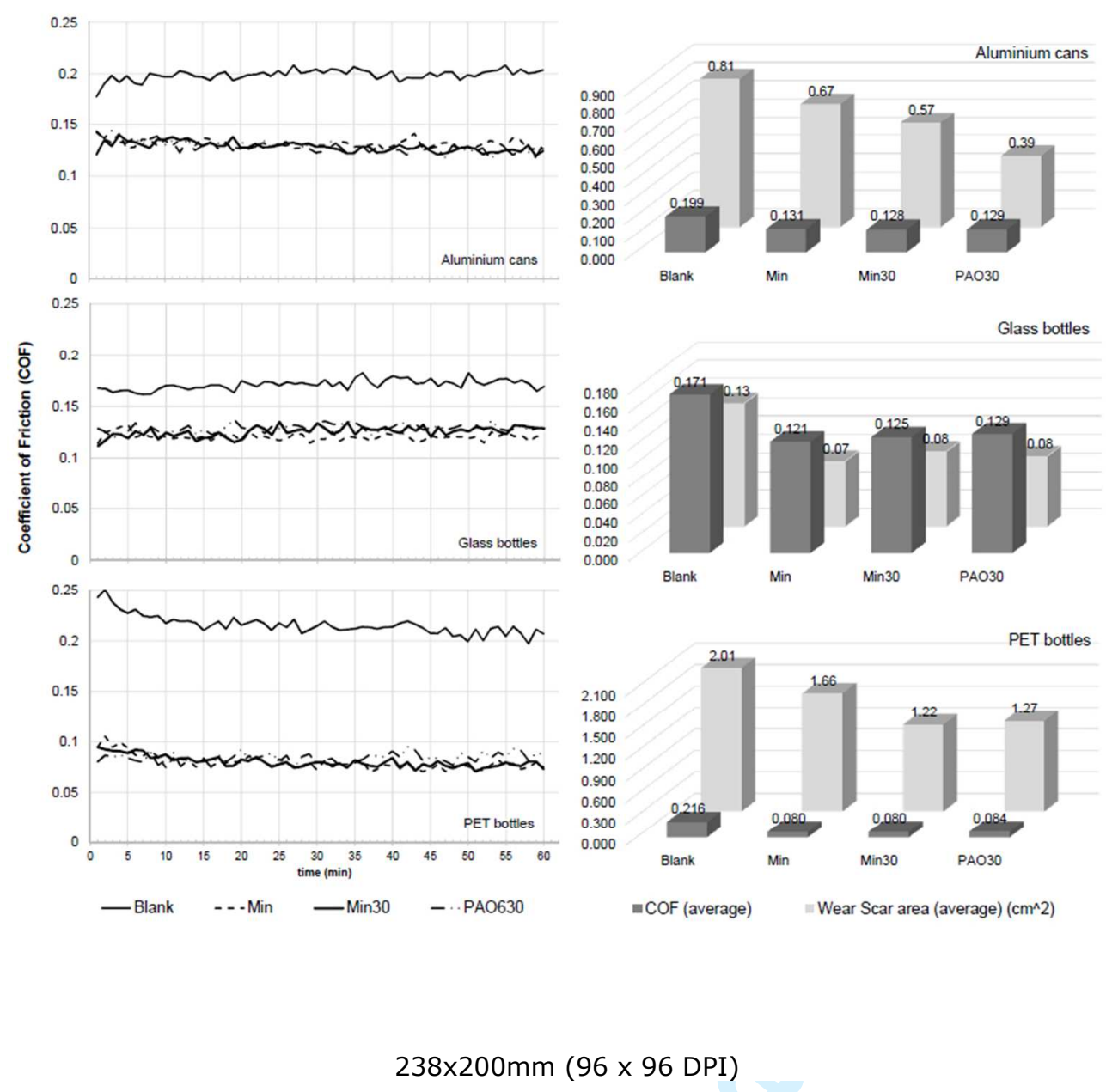




1
2
3
4
5
6
7
8
9
10
11
12
13
14
15
16
17
18
19
20
21
22
23
24
25
26
27
28
29
30
31
32
33
34
35
36
37
38
39
40
41
42
43
44
45
46
47
48
49
50
51
52
53
54
55
56
57
59
60
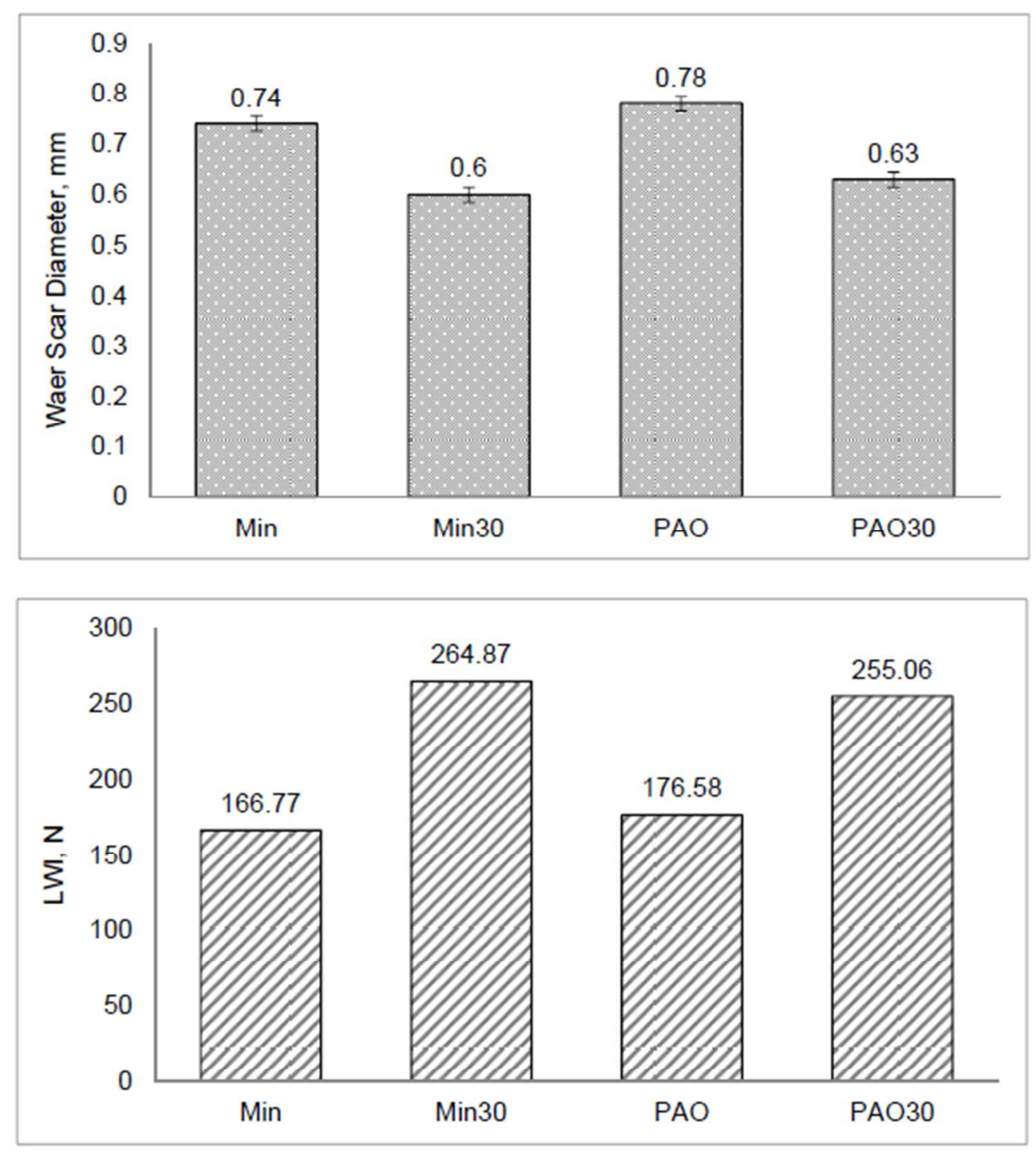

$160 \times 181 \mathrm{~mm}(96 \times 96$ DPI) 